\title{
Một số kết quả nghiên cứu thực nghiệm về bê tông in 3D
}

\author{
Vũ Văn Linh ${ }^{1 *}$, Lê Việt Hùng1, Lê Trung Thành ${ }^{1}$, Nguyễn Công Hậu², Tạ Minh Phương Bảo², Nguyễn Văn Tuấn ${ }^{2}$ \\ ${ }^{1}$ Viện Vật liệu xây dựng, Số 235 Nguyễn Trãi, Q. Thanh Xuân, Hà Nội \\ ${ }^{2}$ Trường Đại học Xây dựng Hà Nội, Số 55 Đường Giải Phóng, Quận Hai Bà Trưng, Hà Nội
}

\section{TỪ KHOÁ}

Bê tông in 3D

Cường độ nén

Khả năng đùn

Khả năng xây

\section{TÓM TÁ́T}

Bài báo này trình bày một số kết quả nghiên cứu thực nghiệm về thành phần và tính chất của bê tông in 3D sử dụng các vật liệu sẵn có ở Việt Nam bao gồm cát (Dmax $=5 \mathrm{~mm}$ ), xi măng, silica fume, tro bay, phụ gia siêu dẻo và nước. Kết quả nghiên cứu thực nghiệm cho thấy hoàn toàn có thể chế tạo được loại bê tông in 3D có độ chảy loang nằm trong khoảng từ 150 đến $200 \mathrm{~mm}$, thời gian thi công $1 \mathrm{~h}$, cường độ nén tuổi 28 ngày là 50 đến $70 \mathrm{MPa}$. Hỗn hợp bê tông in 3D đạt tốc độ đùn hợp lý là 100 đến $140 \mathrm{~mm} / \mathrm{phút}$, tương ứng với tốc độ di chuyển của đầu in là $40 \mathrm{~mm} / \mathrm{s}$ và độ mở đầu in là $20 \mathrm{~mm}$. Hỗn hợp bê tông in $3 \mathrm{D}$ có tỷ lệ nước/chất kết dính và cát/chất kết dính tương ứng là 0,35 và 0,67 cho khả năng xây tốt nhất trong phạm vi nghiên cứu thực nghiệm này.

\section{Giới thiệu}

Sản xuất bằng kỹ thuật in 3D còn được gọi là sản xuất bồi đắp (Additive manufacturing - AM) là phương pháp chế tạo các kết cấu được thiết kế sẵn bằng các đắp chồng các lớp vật liệu lên nhau. Công nghệ in 3D đã phát triển nhanh chóng và đang trở thành xu thế trong nhiều ngành sản xuất, trong đó có ngành xây dựng. So sánh với các kỹ thuật xây dựng thông thường, việc áp dụng các kỹ thuật in 3D trong chế tạo các kết cấu xây dựng có thể mang lại nhiều lợi thế như tự động hóa, giảm chi phí xây dựng (giảm lao động và cốp pha), thời gian thi công, giảm các lỗi trong thi công, phát thải phế thải, tiết kiệm năng lượng và thuận lợi cho việc thực hiện các thiết kế kết cấu tinh vi, phức tạp, có tính thẩm mỹ cao.

Đối với công nghệ in 3D trong xây dựng, vật liệu sử dụng cho quá trình in chính là vật liệu bê tông sử dụng chất kết dính xi măng. Tuy nhiên, khác với công nghệ thi công bê tông truyền thống, công nghệ in 3D không sử dụng cốp pha để đỡ kết cấu sau khi tạo hình. Các kết cấu được thi công bằng bê tông in 3D được tạo ra trên cơ sở các lớp vật liệu được bồi đắp lên nhau, lớp sau chồng lên lớp trước đã được đùn ép ra trước đó. Kỹ thuật này được lặp lại cho đến khi hoàn thành kết cấu. Chính vì vậy, bê tông in 3D ở trạng thái dẻo phải được thiết kế để đáp ứng được các yêu cầu về tính năng như: khả năng đùn của máy in, khả năng xây (khả năng chồng lớp) của khối xây, khả năng thi công, khả năng tạo hình[1].

Các yêu cầu kỹ thuật đối với hỗn hợp bê tông sử dụng trong công nghệ in 3D kiểu "phương pháp đắp lớp" thường khác với những yêu cầu cho hỗn hợp bê tông đúc thông thường. về nguyên tắc, hỗn hợp bê tông thường phải cần một khoảng thời gian khá dài để đóng rắn nên không thể đáp ứng các yêu cầu của việc in 3D. Để tối ưu quy trình in 3D, cần phải có giải pháp kỹ thuật để vượt qua hai hạn chế tồn tại đó là: sự liên kết giữa các lớp bê tông giảm nếu khoảng thời gian in giữa hai lớp tăng; và vật liệu bê tông cần đóng rắn đủ để chịu tải trọng của lớp in tiếp theo mà không bị biến dạng. Việc kiểm soát hai vấn đề trên dẫn đến nghịch lý trong việc tối ưu hóa tốc độ in. Khoảng cách thời gian giữa hai lần in liên tiếp phải đủ dài để đảm bảo cường độ cần thiết, song cũng phải đủ ngắn để đảm bảo sự liên kết giữa các lớp vật liệu bê tông.

Các nghiên cứu về vật liệu bê tông cho công nghệ in $3 \mathrm{D}$ đã được nhiều nghiên cứu thực hiện trong những năm gần đây[2]. Nghiên cứu của tác giả Lê Trung Thành năm 2012 có thể coi là một trong những nghiên cứu đầu tiên phát triển về vật liệu bê tông xi măng cho công nghệ in 3D trong xây dựng[3]. Tác giả đã đưa ra các 
chỉ dẫn về bê tông in tính năng cao cho cho công nghệ in, làm tiền đề cho phát triển các nghiên cứu về bê tông in sau này. Đối với bê tông in 3D, các tính chất của hỗn hợp bê tông như tính công tác, khả năng đùn, khả năng xây và thời gian thi công là các chỉ tiêu quan trọng, quyết định đến khả năng thi công và tính chất của khối bê tông in 3D. Các tính chất này của hỗn hợp bê tông có thể điều chỉnh bằng thành phần cấp phối và bổ sung phụ gia hóa học. Ngoài ra, khả năng thi công cũng như chất lượng của khối in còn phụ thuộc vào các thông số của thiết bị in như hình dạng, độ mở đầu đùn, tốc độ đùn, tốc độ di chuyển đầu đùn. Hiện nay đã có một số bài báo công bố kết quả nghiên cứu về các tính chất của hỗn hợp bê tông và bê tông đóng rắn với các cốt liệu khác nhau[4-6]. Tuy nhiên, các thông số về tính chất của hỗn hợp bê tông phù hợp cho quá trình in phụ thuộc rất nhiều vào thành phần cấp phối, thành phần vật liệu (chất kết dính, cốt liệu, phụ gia) sử dụng, cũng như các thông số của thiết bị in.

Bài báo này trình bày một số kết quả thực nghiệm về tính chất của bê tông in sử dụng vật liệu sẵn có ở Việt Nam và mối tương quan với các thông số của thiết bị in phù hợp cho quá trình in kết cấu.

\section{Vật liệu và phương pháp nghiên cứu}

2.1. Vật liệu nghiên cứu

2.1.1. Xi măng

Trong nghiên cứu này, xi măng được lựa chọn cho sử dụng là xi măng PC40 Nghi Sơn. Các tính chất cơ lý của xi măng được thể hiện ở Bảng 1.

Bảng 1. Các tính chất cơ lý của xi măng.

\begin{tabular}{|c|l|c|c|}
\hline TT & \multicolumn{1}{|c|}{ Chỉ tiêu cơ lý } & Đơn vị & Kết quả \\
\hline 1 & Khối lượng riêng & $\mathrm{g} / \mathrm{cm}^{3}$ & 2,94 \\
\hline 2 & Lượng sót sàng $0,09 \mathrm{~mm}$ & $\%$ & 1,9 \\
\hline 3 & Độ dẻo tiêu chuẩn & $\%$ & 31,5 \\
\hline \multirow{2}{*}{4} & Thời gian đông kết & & \\
& Bắt đầu & phút & 120 \\
& Kết thúc & & 165 \\
\hline 5 & Độ ổn định thể tích & $\mathrm{mm}$ & 1,7 \\
\hline \multirow{2}{*}{6} & Cường độ nén: & & \\
& 3 ngày & $\mathrm{MPa}$ & 33,49 \\
& 28 ngày & & 50,40 \\
\hline
\end{tabular}

\subsubsection{Tro bay}

Tro bay được sử dụng trong nghiên cứu là tro bay (FA) của nhà máy nhiệt điện Quảng Ninh. Hình dạng hạt, các tính chất cơ lý và thành phần hóa của tro bay đốt than phun loại $\mathrm{F}$ được thể hiện ở Hình 1 và Bảng 2 tương ứng.

\subsubsection{Silica fume}

Đề tài sử dụng silicafume (SF) dạng hạt rời do Công ty Elkem cung cấp. Thành phần hạt và tính chất của $\mathrm{SF}$ được trình bày trong Bảng 3. SF sử dụng thỏa mãn các yêu cầu trong TCVN 8827:2011.
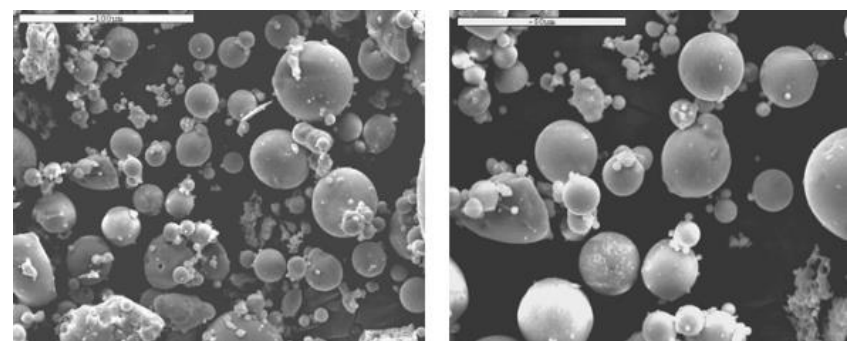

Hình 1. Hình ảnh chụp SEM các hạt tro bay Quảng Ninh.

Bảng 2. Thành phần hạt và tính chất của FA.

\begin{tabular}{|c|l|c|c|c|}
\hline \multirow{2}{*}{ STT } & \multicolumn{1}{|c|}{ Chỉ tiêu thí nghiệm } & \multicolumn{3}{|c|}{ Kết quả } \\
\hline 1 & \% Cỡ hạt có kích thước hạt < D & 10 & 50 & 90 \\
\hline 2 & Đường kính hạt $(\mu \mathrm{m})$ & 2,40 & 5,39 & 10,49 \\
\hline 3 & Kích thước trung bình $(\mu \mathrm{m})$ & \multicolumn{3}{|c|}{5,83} \\
\hline 4 & Khối lượng riêng $\left(\mathrm{g} / \mathrm{cm}^{3}\right)$ & \multicolumn{3}{|c|}{2,40} \\
\hline 5 & Hàm lượng MKN $(\%)$ & \multicolumn{3}{|c|}{6,65} \\
\hline 6 & Độ mịn trên sàng $45 \mu \mathrm{m}(\%)$ & \multicolumn{3}{|c|}{23,20} \\
\hline 7 & Lượng nước yêu cầu $(\%)$ & \multicolumn{3}{|c|}{95} \\
\hline \multirow{2}{*}{8} & Chỉ số hoạt tính cường độ: & \multicolumn{2}{|c|}{79,2} \\
& 7 ngày tuổi (\%) & \multicolumn{2}{|c|}{85,4} \\
\hline
\end{tabular}

Bảng 3. Thành phần hạt và tính chất của SF.

\begin{tabular}{|c|l|c|c|c|c|c|}
\hline STT & \multicolumn{1}{|c|}{ Chỉ tiêu thí nghiệm } & \multicolumn{5}{|c|}{ Kết quả } \\
\hline 1 & \% Cỡ hạt có kích thước hạt $<\mathrm{D}$ & 10 & 25 & 50 & 75 & 90 \\
\hline 2 & Đường kính hạt, $\mu \mathrm{m}$ & 0,119 & 0,129 & 0,141 & 0,154 & 0,167 \\
\hline 3 & Kích thước hạt trung bình, $\mu \mathrm{m}$ & \multicolumn{5}{|c|}{0,141} \\
\hline 4 & Khối lượng riêng, $\mathrm{g} / \mathrm{cm}^{3}$ & \multicolumn{5}{|c|}{2,1} \\
\hline 5 & Khối lượng thể tích, $\mathrm{kg} / \mathrm{m}^{3}$ & \multicolumn{5}{|c|}{250} \\
\hline 6 & Diện tích bề mặt riêng, $\mathrm{cm}^{2} / \mathrm{g}$ & \multicolumn{5}{|c|}{29900} \\
\hline 7 & Chỉ số hoạt tính so với xi măng, \% & \multicolumn{5}{|c|}{110} \\
\hline
\end{tabular}

\subsubsection{Cát}

Trong nghiên cứu này sử dụng một loại cốt liệu là cát có $\mathrm{D}_{\max }=5 \mathrm{~mm}$. Thành phần hạt của cát cho ở Bảng 4 , và tính chất vật lý của cát ở Bảng 5 . Thành phần hạt của cát được xác định theo TCVN 7572-2:2006.

\subsubsection{Nước}

Trong nghiên cứu này, nước sử dụng trong nghiên cứu là nước máy. Các chỉ tiêu chất lượng của nước phù hợp với nước trộn bê tông theo TCVN $4506: 2012$. 
Bảng 4. Thành phần hạt của cốt liệu.

\begin{tabular}{|l|c|c|c|c|c|c|}
\hline \multirow{2}{*}{$\begin{array}{c}\text { Phần còn lại trên } \\
\text { sàng (\%) }\end{array}$} & \multicolumn{5}{|c|}{ Kích thước mắt sàng (mm) } & \begin{tabular}{c} 
Lượng hạt \\
$<\mathbf{0 , 1 4}$ mm \\
\cline { 2 - 6 }
\end{tabular} \\
\cline { 2 - 6 }
\end{tabular}

Bảng 5. Tính chất vật lý của cát.

\begin{tabular}{|c|c|c|c|c|}
\hline STT & Tính chất & Đơn vị & Giá trị & $\begin{array}{c}\text { Phương pháp } \\
\text { thử }\end{array}$ \\
\hline 1 & $\begin{array}{c}\text { Khối lượng thể } \\
\text { tích đồ đống }\end{array}$ & $\mathrm{kg} / \mathrm{m}^{3}$ & 1453 & TCVN 7572:2006 \\
\hline 2 & Khối lượng riêng & $\mathrm{g} / \mathrm{cm}^{3}$ & 2,62 & TCVN 7572:2006 \\
\hline
\end{tabular}

\subsubsection{Phụ gia hóa học}

Nghiên cứu sử dụng loại phụ gia siêu dẻo (PGSD) cho bê tông có tên thương mại là Sika Viscocrete 3000-20 của Sika. Đây là loại phụ gia siêu dẻo trên cơ sở gốc polycarboxylate ether (PCE), độ giảm nước khoảng $36 \%$.

\subsection{Phương pháp nghiên cứu \\ 2.2.1. Quy trình trộn bê tông}

Bước 1: Hỗn hợp vật liệu khô (xi măng, cát, SF, FA) được cho vào cối trộn của máy trộn Hobart vữa xi măng 5 lít và trộn khô với tốc độ chậm trong khoảng 1 phút.

Bước 2: Thêm 70 \% nước và PG hóa học vào hỗn hợp khô và tiếp tục trộn. Tăng dần tốc độ trộn và trộn trong khoảng 1 đến 1,5 phút.

Bước 3: Thêm 30 \% nước còn lại vào hỗn hợp phối liệu và tiếp tục trộn trong khoảng 1 đến 1,5 phút.

\subsubsection{Tính công tác}

Tính công tác của các cấp phối trong nghiên cứu được đánh giá thông qua độ chảy loang của hỗn hợp bê tông. Độ chảy loang được đo bằng côn nhỏ (Hình 2) theo TCVN 3121-3:2003. Trong nghiên cứu này, độ chảy loang của các hỗn hợp được điều chỉnh bằng PGSD để đạt yêu cầu tối thiểu là $150 \mathrm{~mm}$.

\subsubsection{Cường độ nén}

Cường độ nén của bê tông trong nghiên cứu được xác định theo tiêu chuẩn TCVN 3121-11:2003 trên mẫu thử có kích thước $40 \times 40 \times 160$ mm ở các tuổi 3 ngày, 7 ngày và 28 ngày.
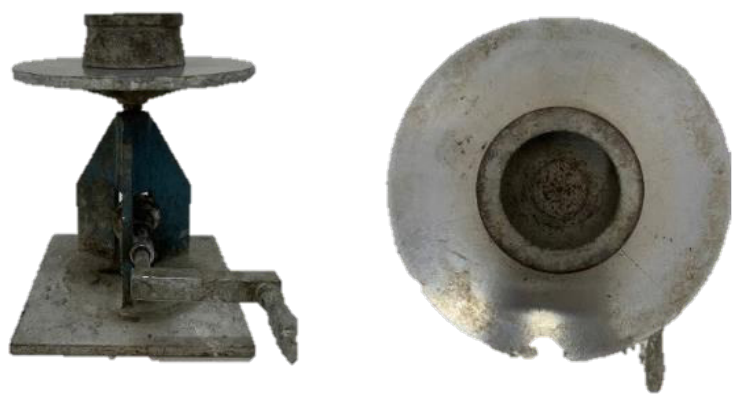

Hình 2. Bàn dằn và côn đo độ chảy loang.

\subsubsection{Khả năng đùn và khả năng xây}

Sau khi trộn và thử nghiệm tính công tác, các cấp phối được lắp vào hệ thống thí nghiệm máy in để tiến hành thử nghiệm khả năng đùn và khả năng xây (Hình 3). Khả năng đùn được thí nghiệm và đánh giá bằng quan sát và đo hình dạng, kích thước của sợi đùn. Khả năng xây được đánh giá bằng cách chồng các lớp vật liệu đùn ép lên nhau. Hỗn hợp bê tông có khả năng xây tốt là hỗn hợp có số lớp chồng lên nhau nhiều nhất mà khối bê tông không bị biến dạng hoặc đổ sập.

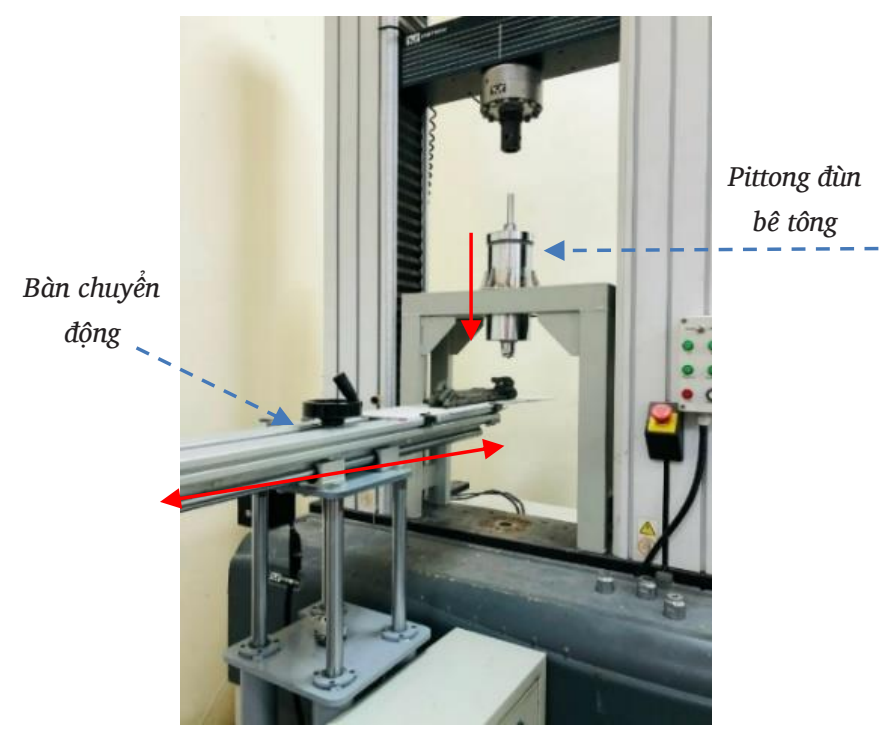

Hình 3. Hệ thống thí nghiệm in bê tông.

\subsubsection{Quy trình thử nghiệm}

Hỗn hợp bê tông sau khi đạt yêu cầu về độ chảy loang được sử dụng để thí nghiệm các tính chất của bê tông in.

Bước 1: Điền đầy vật liệu vào pitong.

Bước 2: Lắp đặt pitong vào vị trí.

Bước 3: Tiến hành thí nghiệm tính chất của hỗn hợp bê tông bao gồm khả năng đùn và khả năng xây. Vật liệu được đùn với các vận tốc khác nhau, lần lượt là $60,80,100,120,140,160$ và 180 mm/phút. Tốc độ di chuyển của đầu in được giữ nguyên là $40 \mathrm{~mm} / \mathrm{s}$. 

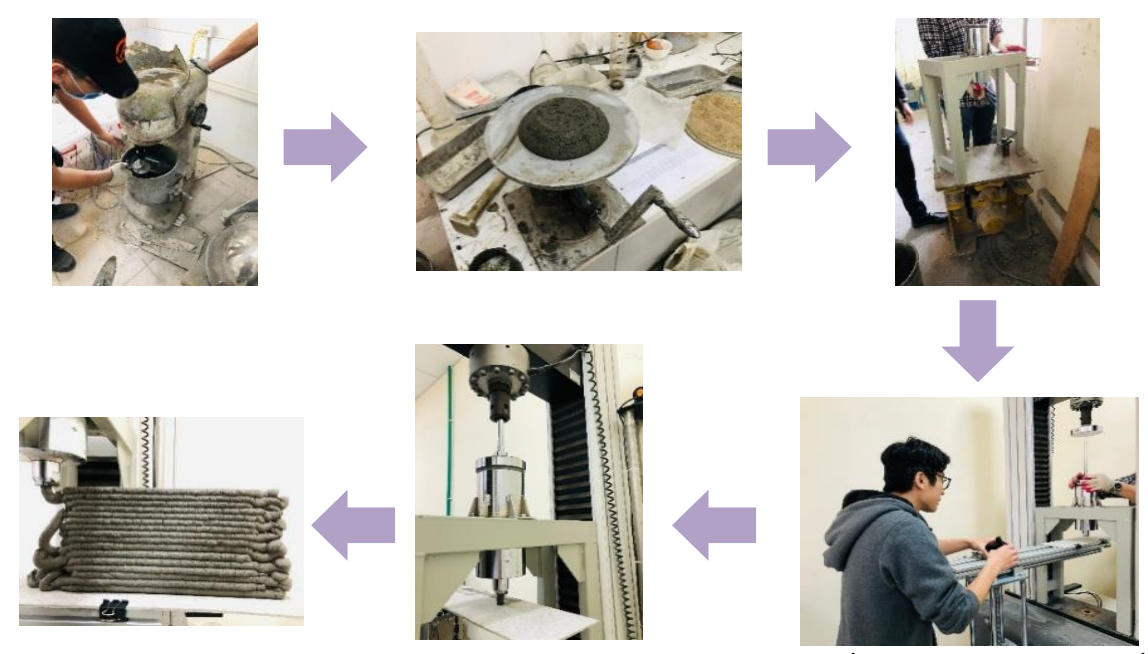

Hình 4. Quy trình trộn hỗn hợp bê tông và thí nghiệm các tính chất của bê tông in thực tế.

\subsection{Cấp phối nghiên cứu}

Trong nghiên cứu này, các cấp phối thí nghiệm được lựa chọn dựa trên cơ sở các kết quả nghiên cứu của tác giả Lê Trung Thành [3] với hàm lượng chất kết dính bao gồm $70 \%$ xi măng, $20 \% \mathrm{FA}$, và $10 \%$ SF. Với cường độ nén 28 ngày mục tiêu lớn hơn $50 \mathrm{MPa}$, hai tỷ lệ $\mathrm{N} / \mathrm{CKD}$ được lựa chọn là 0,35 và 0,40 . Hàm lượng PGSD theo tổng hàm lượng chất kết dính được sử dụng để điều chỉnh độ chảy loang của các hỗn hợp đạt được 150 đến $200 \mathrm{~mm}$. Các cấp phối cụ thể thể hiện trong Bảng 6.

\section{Kết quả nghiên cứu và bàn luận}

\subsection{Tính công tác}

Trong nghiên cứu này tính công tác được đánh giá qua độ chảy loang của hỗn hợp bê tông, và được khống chế trong khoảng 150 $200 \mathrm{~mm}$ bằng cách thay đổi lượng dùng phụ gia siêu dẻo. Thời gian thi công (open time) của hỗn hợp bê tông in được hiểu là khoảng thời gian mà hỗn hợp bê tông vẫn duy trì được độ dẻo và đảm bảo tính ổn định của quá trình in.

Trong nghiên cứu này, tổn thất độ chảy của hỗn hợp bê tông in theo thời gian được xác định ngay sau lúc trộn (tính là thời điểm 0 ), 30 phút và 60 phút. Kết quả thể hiện trong Bảng 7 và Hình 5 .

Bảng 6.Các cấp phối bê tông in nghiên cứu.

\begin{tabular}{|c|c|c|c|c|c|c|c|}
\hline STT & Cấp phối & N/CKD & Cát/CKD & PGSD (\%) & FA (\%) & SF (\%) & CKD $\left(\mathrm{kg} / \mathrm{m}^{3}\right)$ \\
\hline 1 & w.b0.35c0.67 & 0,35 & 0,67 & 0,22 & 20 & 10 & 1040 \\
\hline 2 & w.b0.35c1.0 & 0,35 & 1,0 & 0,30 & 20 & 10 & 918 \\
\hline 3 & w.b0.35c1.5 & 0,35 & 1,5 & 0,35 & 20 & 10 & 781 \\
\hline 4 & w.b0.40c0.67 & 0,40 & 0,67 & 0,12 & 20 & 10 & 988 \\
\hline 5 & w.b0.40c1.0 & 0,40 & 1,0 & 0,17 & 20 & 10 & 878 \\
\hline 6 & w.b0.40c1.5 & 0,40 & 1,5 & 0,25 & 20 & 10 & 752 \\
\hline
\end{tabular}

Bảng 7. Giá trị độ chảy loang của các cấp phối bê tông.

\begin{tabular}{|c|c|c|c|c|}
\hline STT & Cấp phối & Độ chảy loang sau trộn $\mathbf{( m m )}$ & Độ chảy loang sau 1h (mm) & Tỉ lệ tổn thất độ chảy loang (\%) \\
\hline 1 & w.b0.35c0.67 & 150 & 135 & 10 \\
\hline 2 & w.b0.35c1.0 & 150 & 150 & 0 \\
\hline 3 & w.b0.35c1.5 & 160 & 153 & 4 \\
\hline 4 & w.b0.40c0.67 & 153 & 145 & 5 \\
\hline 5 & w.b0.40c1.0 & 147 & 127 & 14 \\
\hline 6 & w.b0.40c1.5 & 148 & 127 & 14 \\
\hline
\end{tabular}

Ghi chú: ký hiệu w.b0.35 thể hiện cấp phối có tỷ lệ N/CKD bằng 0,35 theo khối lượng; c0.67 thể hiện tỷ lệ C/CKD bằng 0,67 theo khối lượng. 


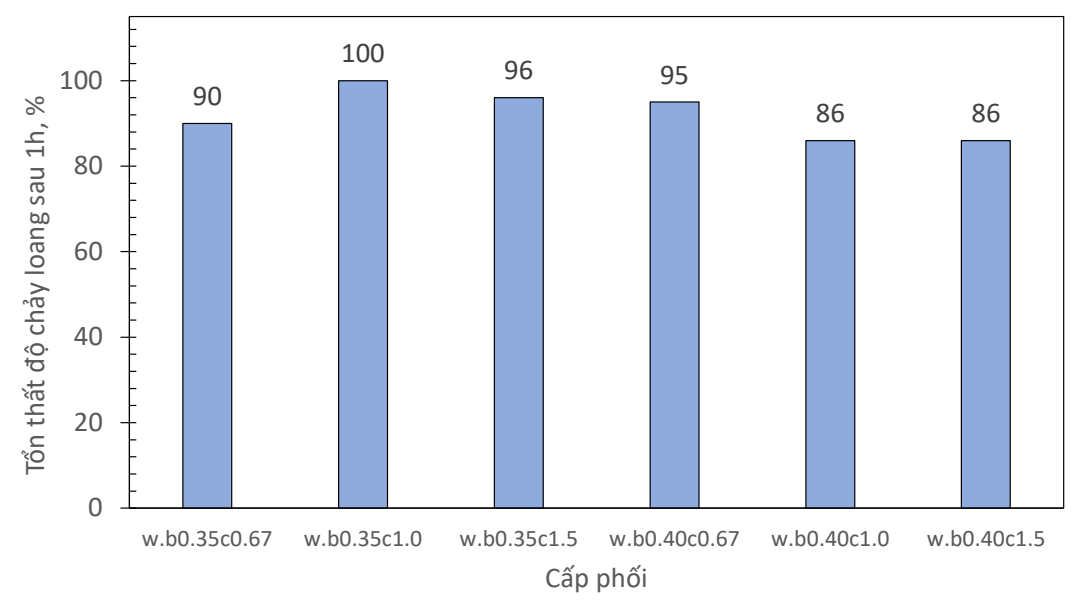

Hình 5. Tổn thất độ chảy loang của các cấp phối thí nghiệm sau 1h.

Thời gian thi công bị ảnh hưởng trực tiếp bởi khả năng duy trì độ chảy loang của hỗn hợp bê tông. Độ chảy loang của các cấp phối nghiên cứu bị sụt giảm trong khoảng $4 \%$ đến $14 \%$ tùy theo từng cấp phối khác nhau. Cấp phối w.b0.35c1.0 có khả năng duy trì độ chảy loang tốt khi giữ nguyên được 100 \% độ chảy ban đầu.

\subsection{Cường độ nén}

Cường độ nén theo các tuổi của các cấp phối nghiên cứu thể hiện ở Bảng 8 và được biểu diễn trên Hình 6 .

Kết quả thí nghiệm cho thấy cường độ nén của cấp phối w.b0.35c0.67 đạt giá trị lớn nhất là $78,85 \mathrm{MPa}$ và thấp nhất là của cấp phối w.b0.40c0.67 đạt 61,45 MPa. Tuy nhiên, tất cả cường độ nén tuổi 28 ngày của các mẫu đều lớn hơn $50 \mathrm{MPa}$ - cấp cường độ yêu cầu đặt ra. Cường độ của bê tông phát triển mạnh trong 7 ngày đầu tiên và tăng chậm trong khoảng thời gian sau đó.

Tỷ lệ N/CKD ảnh hưởng mạnh tới cường độ chịu nén của bê tông. Tỷ lệ $\mathrm{N} / \mathrm{CKD}$ càng thấp cho bê tông có cường độ chịu nén càng cao. Ngoài ra tỷ lệ $\mathrm{C} / \mathrm{CKD}$ cũng ảnh hưởng tới cường độ nén của mẫu và sự ảnh hưởng này cũng khá lớn.

Bảng 8. Cường độ nén của bê tông in trong nghiên cứu.

\begin{tabular}{|c|c|c|c|c|}
\hline \multirow{2}{*}{ STT } & \multirow{2}{*}{ Cấp phối } & \multicolumn{3}{|c|}{ Cường độ nén (MPa) } \\
\cline { 3 - 5 } & & 3 ngày & 7 ngày & 28 ngày \\
\hline 1 & w.b0.35c0.67 & 51,16 & 60,23 & 78,85 \\
\hline 2 & w.b0.35c1.0 & 43,77 & 48,44 & 64,4 \\
\hline 3 & w.b0.35c1.5 & 40,03 & 53,19 & 69,08 \\
\hline 4 & w.b0.40c0.67 & 48,23 & 56,95 & 61,45 \\
\hline 5 & w.b0.40c1.0 & 36,63 & 48,83 & 67,62 \\
\hline 6 & w.b0.40c1.5 & 38,92 & 50,30 & 67,31 \\
\hline
\end{tabular}

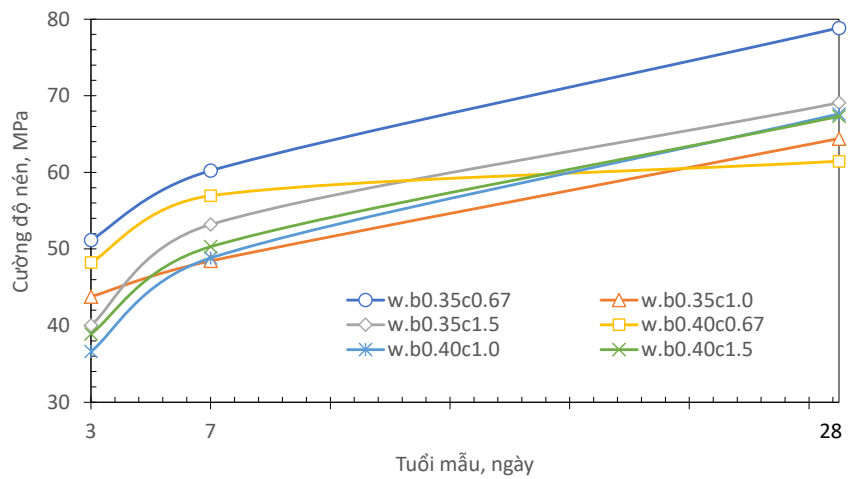

Hình 6. Sự phát triển cường độ nén của các cấp phối nghiên cứu.

\subsection{Khả năng đùn}

Trong nghiên cứu này, nhìn chung khả năng đùn của các cấp phối là tốt, tất cả các cấp phối đều được máy mô phỏng đùn một cách dễ dàng. Tuy nhiên tốc độ đùn là nhân tố ảnh hưởng lớn đến khả năng đùn của các cấp phối. Chú ý rằng $\mathrm{D}_{\max }$ của cát $=5 \mathrm{~mm}$, và đường kính lỗ mở của đầu in là $20 \mathrm{~mm}$, tốc độ đùn từ 40-160 mm/ph, tốc độ di chuyển của đầu in là $40 \mathrm{~mm} / \mathrm{s}$.

Như trong Hình 7a), b), c), khi tốc độ đùn của máy in thấp (lần lượt là 40,60, $80 \mathrm{~mm}$ /phút) thì các sợi vật liệu được đùn ra không đồng đều, đứt gãy vì lượng vật liệu được đùn ra quá ít. Rõ ràng ở các tốc độ thấp từ 40 đến $80 \mathrm{~mm} /$ phút không thể tiến hành chồng lớp để tạo ra các khối bê tông có tính ổn định. Khi tăng tốc độ đùn lên cao hơn, khoảng 100 đến $140 \mathrm{~mm} /$ phút, các đường in đều hơn, đẹp hơn, đường in có đường kính đều, bề mặt mịn và lượng vật liệu đủ lớn để có thể chồng lớp. Ở tốc độ cao hơn như 160 và 180 mm/phút thì sợi đùn có bề mặt xấu, vật liệu bị đùn ra nhiều và dễ đứt gãy, mất ổn định (Hình 8).

Kết quả nghiên cứu của các cấp phối khác cho ra kết quả tương tự. Khả năng đùn của các cấp phối chỉ tốt khi tốc độ đùn của máy in là từ 100 đến 140 mm/phút là tốc độ hợp lý cho 6 cấp phối nghiên cứu. 
a)

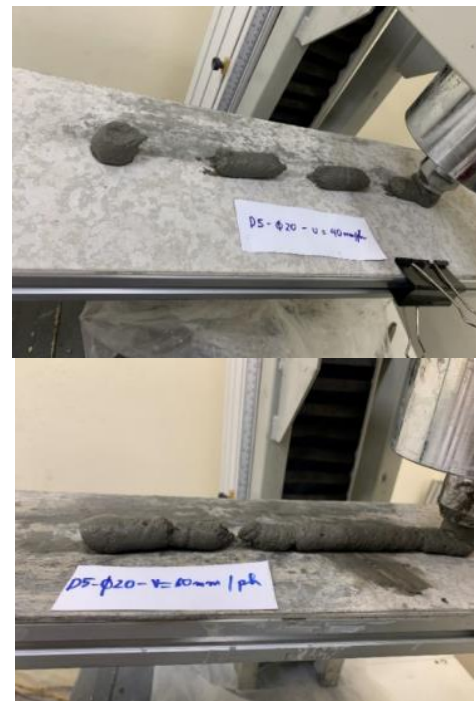

b)

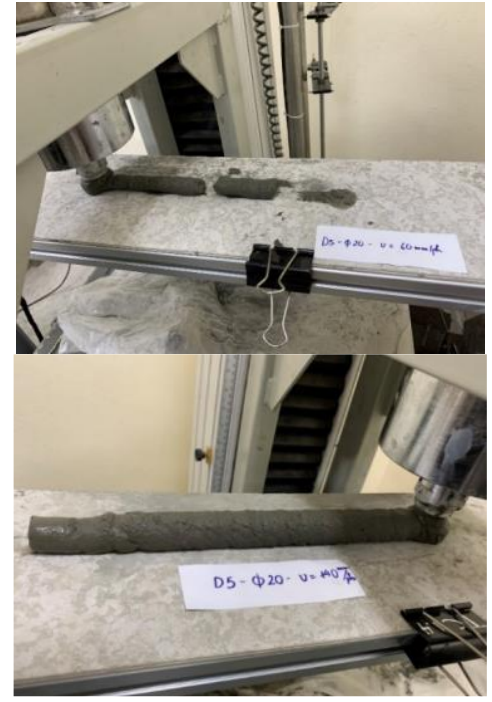

Hình 7. Khả năng đùn của hỗn hợp bê tông in với các tốc độ đùn khác nhau (a) 40, (b) 60, (c) 80, (d) $140 \mathrm{~mm} / \mathrm{ph}$.
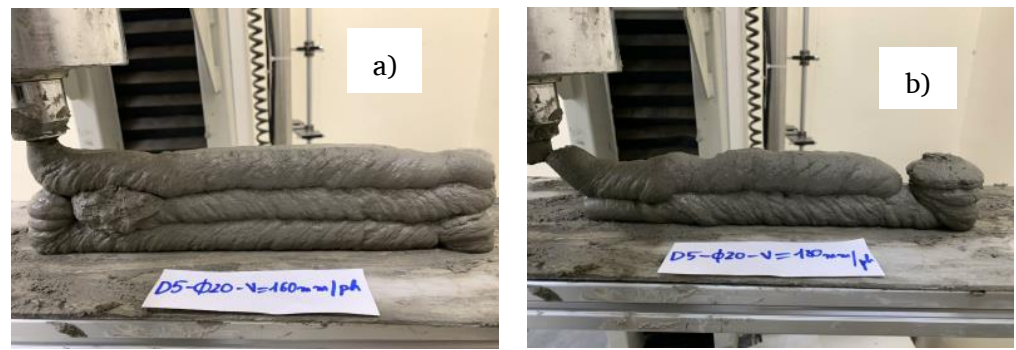

Hình 8. Đánh giá khả năng đùn của hỗn hợp bê tông in với các tốc độ đùn khác nhau (a) $160 \mathrm{~mm} /$ phút, (b) $180 \mathrm{~mm} /$ phút.
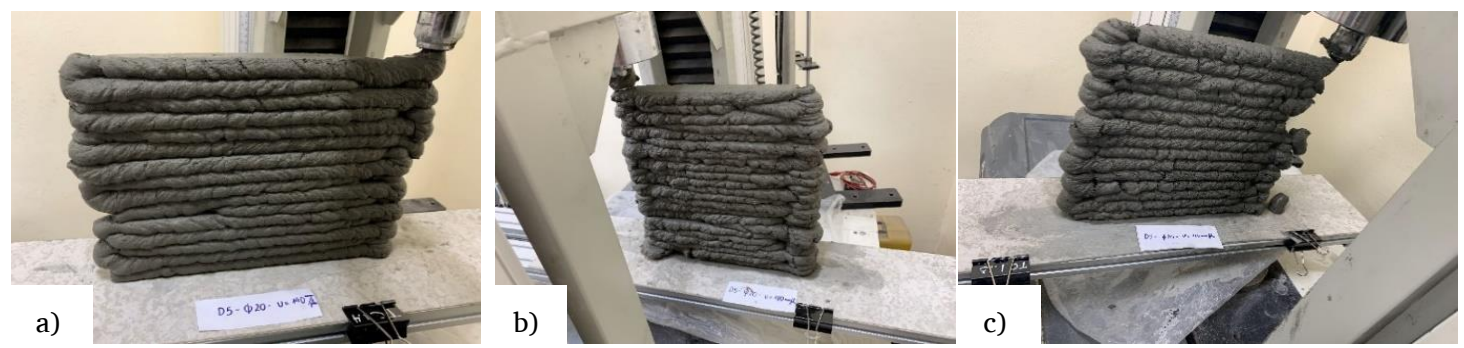

Hình 9. Đánh giá khả năng xây của hỗn hợp bê tông in với với tỷ lệ N/CKD = 0,35 và các tỷ lệ C/CKD khác nhau: (a) 0,67 , (b) 1,0 , (c) 1,5 .

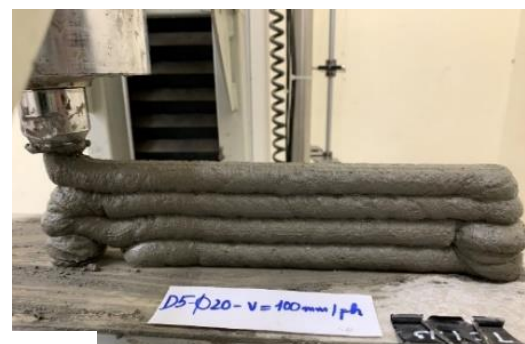

a)
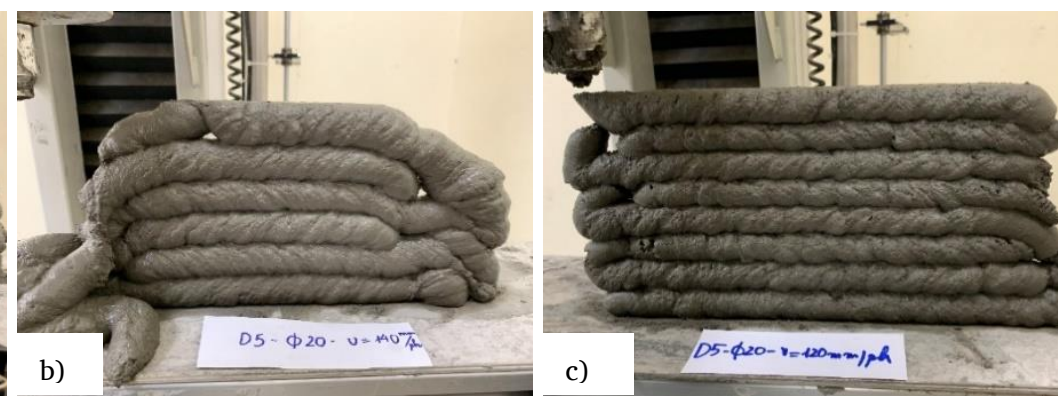

Hình 10. Đánh giá khả năng xây của hỗn hợp bê tông in với với tỷ lệ N/CKD = 0,40 và các tỷ lệ C/CKD khác nhau: (a) 0,67 , (b) 1,0, (c) 1,5. 
Bảng 9. Đánh giá khả năng xây của các cấp phối bê tông in nghiên cứu.

\begin{tabular}{|c|c|c|c|l|}
\hline STT & Cấp phối & N /CKD & C/CKD & \multicolumn{1}{|c|}{ Đánh giá về khả năng xây } \\
\hline 1 & w.b0.35c0.67 & 0,35 & 0,67 & $\begin{array}{l}\text { Cấp phối này chồng được nhiều lớp. Bề mặt đường in mịn, khả năng xây và khả năng liên kết } \\
\text { giữa các lớp đều tốt. }\end{array}$ \\
\hline 2 & w.b0.35c1.0 & 0,35 & 1,0 & $\begin{array}{l}\text { Cấp phối chồng lớp tốt. Tuy nhiên vì tăng lượng dùng cát nên bề mặt hơi xù xì, xấu. Khả năng } \\
\text { xây và liên kêt giữa các lớp đều ổn. }\end{array}$ \\
\hline 3 & w.b0.35c1.5 & 0,35 & 1,5 & $\begin{array}{l}\text { Cấp phối chồng lớp tốt. Khả năng xây và khả năng liên kết giữa các lớp tạm ổn. Tuy nhiên bề } \\
\text { mặt quá xù xì do dùng nhiều cát, không đạt yêu cầu. }\end{array}$ \\
\hline 4 & w.b0.40c0.67 & 0,40 & 0,67 & $\begin{array}{l}\text { Cấp phối có khả năng chồng lớp kém, đến lớp thứ } 5 \text { thì không chồng được. Đường in đều, mịn vì } \\
\text { dùng nhiều nước và ít cát, tuy nhiên không đạt yêu cầu về khả năng xây. }\end{array}$ \\
\hline 5 & w.b0.40c1.0 & 0,40 & 1,0 & $\begin{array}{l}\text { Cấp phối có cải thiện hơn cấp phối trước khi tăng lượng cát sử dụng. Tuy nhiên đường in vẫn } \\
\text { khó có thể chồng được nhiều lớp, chưa đạt yêu cầu về khả năng xây. }\end{array}$ \\
\hline 6 & w.b0.40c1.5 & 0,40 & 1,5 & $\begin{array}{l}\text { Cấp phối tốt nhất trong các cấp phối có tî lệ N/CKD = 0,4; bề mặt đường in khá đẹp và mịn. Tuy } \\
\text { nhiên đường in liên kết không tốt và rất dễ đổ. }\end{array}$ \\
\hline
\end{tabular}

\subsection{Khả năng xây}

Khả năng xây là yếu tố rất quan trọng với bê tông in 3D. Trong nghiên cứu này, khả năng xây phụ thuộc vào nhiều yếu tố, đặc biệt là các tỉ lệ $\mathrm{N} / \mathrm{CKD}$ và $\mathrm{C} / \mathrm{CKD}$. Nghiên cứu này đánh giá sự ảnh hưởng của 2 tỉ lệ $\mathrm{N} / \mathrm{CKD}(0,35$ và 0,40$)$ và 3 tỉ lệ $\mathrm{C} / \mathrm{CKD}(0,67-1,0-1,5)$. Kết quả nghiên cứu cụ thể của 6 cấp phối được trình bày ở Hình 9 , Hình 10 và đánh giá kết quả ở Bảng 9 . Chú ý rằng tốc độ đùn của các thí nghiệm nằm trong khoảng 100 đến $140 \mathrm{~mm} /$ phút.

Từ các kết quả trên, một số kết luận về khả năng xây của các cấp phối có thể rút ra như sau:
Tỉ lệ N/CKD phù hợp là 0,35 cho bê tông in tương ứng với hệ thống thí nghiệm; tỉ lệ 0,40 không phù hợp với bê tông in 3D trong nghiên cứu này.

Tỉ lệ N/CKD là yếu tố quan trọng nhất ảnh hưởng đến khả năng xây. Tỉ lệ này phù hợp thì các cấp phối có khả năng xây rất tốt, tỉ lệ này cao sẽ làm các cấp phối không thể chồng lớp và dễ đổ.

Tỉ lệ C/CKD tăng có thể làm cải thiện khả năng xây. Tuy nhiên nếu tỉ kệ N/CKD không phù hợp thì tăng lượng dùng cát cũng không cải thiện được khả năng xây.

Từ các kết quả nghiên cứu trên, nhóm đề tài đưa ra cấp phối tối ưu ở Bảng 10.

Bảng 10. Cấp phối bê tông in tối ưu được lựa chọn.

\begin{tabular}{|c|c|c|c|c|c|c|c|}
\hline N/CKD & C/CKD & FA (\%) & SF (\%) & PGSD (\%) & Xi măng (kg/m $\left.{ }^{3}\right)$ & Tốc độ đầu in (mm/s) & Tốc độ đùn (mm/ph) \\
\hline 0,35 & 0,67 & 20 & 10 & 0,22 & 1040 & 40 & $100-140$ \\
\hline
\end{tabular}

\section{Kết luận}

Từ các kết quả nghiên cứu cho phép đưa ra một số kết luận như sau:

- Bê tông in có thể được chế tạo với các vật liệu sẵn có ở Việt Nam như cát $\left(D_{\max }=5 \mathrm{~mm}\right)$, xi măng, $\mathrm{SF}, \mathrm{FA}, \mathrm{PGSD}$ và nước.

- Khả năng xây bị ảnh hưởng lớn bởi các tỷ lệ $\mathrm{N} / \mathrm{CKD}$ và $\mathrm{C} / \mathrm{CKD}$, trong đó cấp phối tốt nhất đối với khả năng xây trong nghiên cứu này là hỗn hợp bê tông có tỷ lệ $\mathrm{N} / \mathrm{CKD}=0,35 ; \mathrm{C} / \mathrm{CKD}=0,67$; trong đó hàm lượng phụ gia khoáng sử dụng là $10 \%$ SF kết hợp 20 \% FA.

- Cấp phối bê tông phù hợp cho quá trình in với tính công tác được xác định thông qua độ chảy loang trong khoảng 150 đến $200 \mathrm{~mm}$, thời gian thi công kéo dài trên $1 \mathrm{~h}$, cường độ nén tuổi 28 ngày đạt trong khoảng 50 đến $70 \mathrm{MPa}$.

- Khả năng đùn của các cấp phối phụ thuộc rất nhiều vào tốc độ đùn. Tốc độ đùn hợp lý là 100 đến $140 \mathrm{~mm} /$ phút ứng với tốc độ di chuyển của đầu in là $40 \mathrm{~mm} / \mathrm{s}$ và độ mở đầu in là $20 \mathrm{~mm}$.

Bài báo này là một phần kết quả nghiên cứu của nhiệm vụ cấp Bộ Xây dựng "Nghiên cứu ứng dụng công nghệ in 3D trong chế tạo vật liệu xây dựng tính năng cao", mã số RD 42-20. Nhóm tác giả trân trọng cảm ơn Bộ Xây dựng đã tạo điều kiện và hỗ trợ chúng tôi hoàn thành nghiên cứu mang tính đột phá, góp phần vào sự phát triển công nghệ xây dựng trong cuộc Cách mạng công nghiệp lần thứ 4 tại Việt Nam.

\section{Tài liệu tham khảo}

[1]. Z. Li et al, "Fresh and hardened properties of extrusion-based 3D-printed cementitious materials: a review",Sustainability,vol. 12, no. 14, p. 5628, 2020.

[2]. G. Ma, L. Wang, and Y. J. S. C. T. S. Ju, "State-of-the-art of 3D printing technology of cementitious material-An emerging technique for construction", Science China Technological Sciences, vol. 61, no. 4, pp. 475495, 2018.

[3]. T. T. Le et al., "Mix design and fresh properties for high-performance printing concrete", Materials and Structures, vol. 45, no. 8, pp. 1221-1232, 2012.

[4]. G. Ma, Z. Li, L. J. C. Wang, and b. materials, "Printable properties of cementitious material containing copper tailings for extrusion based 3D printing", Construction and Building Materials, vol. 162, pp. 613-627, 2018.

[5]. Y. Zhang et al., "Fresh properties of a novel 3D printing concrete ink", Construction and Building Materials, vol. 174, pp. 263-271, 2018.

[6]. J. Lin, X. Wu, W. Yang, R. Zhao, and L. Qiao, "The influence of fine aggregates on the 3D printing performance," in IOP Conference Series: Materials Science and Engineering, 2018, vol. 292, no. 1, p. 012079: IOP Publishing. 